\begin{tabular}{|c|c|}
\hline $\begin{array}{l}\text { Additional } \\
\text { Information }\end{array}$ & $\begin{array}{l}\text { NOTICE: This is the author's version of a work that was accepted for } \\
\text { publication in Analytica Chimica Acta. Changes resulting from the } \\
\text { publishing process, such as peer review, editing, corrections, structural } \\
\text { formatting, and other quality control mechanisms may not be reflected } \\
\text { in this document. Changes may have been made to this work since it } \\
\text { was submitted for publication. A definitive version was subsequently } \\
\text { published in Analytica Chimica Acta, Vol. } 614 \text {, Issue 1, (2008). doi: } \\
\text { http://doi.org/10.1016/j.aca.2008.02.069 }\end{array}$ \\
\hline
\end{tabular}




\title{
Phosphate Selective Fluorescent Sensing Microspheres Based on Uranyl Salophene Ionophores
}

\author{
Katarzyna Wygladacz ${ }^{1}$, Yu Qin ${ }^{2}$, Wojciech Wroblewski ${ }^{3}$ and Eric Bakker ${ }^{1,4 *}$ \\ Received: ( ) \\ ${ }^{1}$ Department of Chemistry, Purdue University, West Lafayette, IN 47907 \\ ${ }^{2}$ Department of Chemistry, Renmin University of China, Beijing, People's Republic of \\ China \\ ${ }^{3}$ Department of Chemistry, Warsaw University of Technology, Warsaw, Poland \\ ${ }^{4}$ Nanochemistry Research Institute, Department of Applied Chemistry, Curtin University \\ of Technology, Perth, WA 6845, Australia.
}

*e-mail: e.bakker@curtin.edu.au 


\begin{abstract}
Optical dihydrogen phosphate-selective sensors that function on the basis of bulk optode principles and are based on two different uranyl salophene ionophores are reported here for the first time. The influence of the optode composition and measuring conditions such as sample $\mathrm{pH}$ on the optode response are characterized, along with sensor selectivity and long-term stability. Three plasticizers of different polarity are considered for optode fabrication: bis(2-ethylhexyl)sebacate (DOS), dodecyl 2-nitrophenyl ether (o-NPDDE), o-nitrophenyloctylether (o-NPOE). The compounds 9-(diethylamino)-5(octadecanoylimino)-5H-benzo[a]phenoxazine (ETH 5294, chromoionophore I) and 9(diethylamino)-5-[(2-octyldecyl)imino]benzo[a]phenoxazine $\quad($ ETH $\quad 5350$, chromoionophore III) are used as $\mathrm{H}^{+}$-selective fluoroionophores that also act as reference ionophores. The resulting optode-based sensors are compared with their ion-selective electrode (ISE) counterparts, and it is revealed that optodes are better suited for operation at physiological $\mathrm{pH}$. Dihydrogen phosphate-selective optode sensors of optimized composition are fabricated in microsphere format and preliminary measurements in diluted sheep blood samples are presented.
\end{abstract}

Keywords: phosphate sensor, optical sensors, ionophore, uranyl salophene, microsphere sensors 


\section{Introduction}

Phosphorus plays an essential role in agri- and horticulture but also causes eutrophication of natural water. From a biomedical point of view, phosphorus is an essential nutrient for multiple and diverse biological functions, including cellular signal transduction, mineral metabolism, and energy exchange. While the predominant portion of total body phosphorus is stored in the bones and teeth, intracellular phosphorus exists in the form of organic compounds such as adenosine triphosphate (ATP) and as free anions such as monohydrogen phosphate $\left(\mathrm{HPO}_{4}{ }^{2-}\right)$, which are commonly referred to as phosphate. Plasma phosphorus primarily occurs in the form of inorganic phosphate, whose speciation is $\mathrm{pH}$ dependent.

The diversity of applications stimulated a considerable amount of research to develop robust sensors for the phosphate monitoring in clinical and environmental samples. Flowinjection analysis (FI) [1-3], colorimetric methods [4-7] and electroanalytical techniques [8-17] have been explored to this end. In view of chemical sensor applications, considerable effort has been put to design and synthesize new receptor molecules capable of the chemical recognition of different phosphate species. In addition to the uranyl salophene receptors discussed further below, cobalt phthalocyanine [15] bis(dibenzyltin)oxide [13], zwitterionic bis(guanidinium) [16], 3-decyl-1,5,8triazacyclodecane-2,4-dione (N3-cyclic amine) [17], bis(p-methylbenzyl)tin dichloride [18], tris(3-chlorodimethylstannylpropyl)chlorostannane

[19], bis(dichloromethylstannylpropyl)dichlorostannane [19], 1,3-bis(chlorodimethylstannyl)-

propane [19], hexyl p-trifloroacetylbenzoate [20], 3-(10-undecyl)-1,5,8triazocyclodecane-2,4-dione [21], and vanadyl salophene [22] have been proposed for phosphate recognition.

Due to the speciation of phosphate forms only a few analytical techniques can be applied for speciation selective phosphate analysis. Most of them are able to determine total 
phosphate concentration in the sample. Among the large palette of analytical techniques available, ion-selective electrodes (ISEs) and their ion-selective fluorescent bulk optode counterparts are key techniques capable to distinguish the phosphate forms and measure the activity of free ions in the sample. ISEs have routinely been used for clinical analysis purposes. Although ISEs and bulk optodes are constructed using the same family of receptors (ionophore, ionic sites) [23] they are based on different response mechanisms [23]. Bulk optodes utilize a mass transport process and follow coextraction and complexation chemistry principles. Optodes are doped with two ionophores, suspended in an appropriate inert polymeric material. While one of the ionophores binds the ion of interest, the second acts as receptor for protons and exhibits spectral properties. The sensor responses based on a competitive or cooperative binding of protons and analyte. The measuring range of optode sensors can be easily tuned to the desired range by varying the composition or/and experimental conditions [23, 24].

The possibility of highly advanced sensor miniaturization, which translates into shorter response times and smaller required sample volume are an advantage of optical microspheres over ISEs. Such optode microspheres are compatible with numerous techniques and platforms such as optical fibers [25] or analytical flow cytometry [26]. So far, various microsphere based optode have been reported in the literature [25, 27-30]. They were successfully applied for the determination of different samples, including in trace analysis [29, 30].

The goal of this study was to design phosphate selective microsphere optical sensors in view of realizing a suspension array based total clinical analysis system. For the purpose of this study, two electroneutral derivatives of uranyl salophene, originally introduced in Reinhoudt's group, were of particular interest [31-35]. Here, t-butyl- and methylsubstituted uranyl salophene compounds (phosphate ionophore I and II, respectively) were applied for the optode-sensor fabrication with the combination of two chromoionophores of different basicity (ETH 5294 and ETH 5350). Optode films and optode microspheres were optimized and applied to the determination of dihydrogen phosphate in diluted sheep blood. 


\section{Experimental}

Reagents. Poly(vinyl chloride) (PVC), bis(2-ethylhexyl)sebacate (DOS), dodecyl 2nitrophenyl ether (o-NPDDE), o-nitrophenyloctylether (o-NPOE), 9-(diethylamino)-5(octadecanoylimino)-5H-benzo[a]phenoxazine (ETH 5294, chromoionophore I), 9(diethylamino)-5-[(2-octyldecyl)imino]benzo[a]phenoxazine $\quad$ (ETH 5350, chromoionophore III), 4',5'-dibromofluorescein octadecyl ester ETH 7075, chromoionophore VI), tridodecylmethylammonium chloride (TDMAC), tetrahydrofuran (THF), 2-(N-morpholino) ethane sulfonic acid (MES) were purchased from Fluka (Milwaukee, WI). $\quad \operatorname{DiOC}_{14}(3), \quad$ hydroxyethanesulfonate (3,3'-ditetra decyloxacarbocyanine, hydroxyethanesulfonate) was reagent grade purchased from Biotium, Inc. (Hayward, CA). Phosphate ionophore I and II were synthesized according to the procedure described elsewhere [32]. All solutions were prepared with freshly deionized water $(18 \mathrm{M} \Omega \mathrm{cm})$ using a Nanopure Millipore water purification system. Salts, acids and bases of the highest available quality were used.

ISE membranes. The membrane used for fabrication of the phosphate-selective electrodes were doped with $28.7 \mathrm{mmol} / \mathrm{kg}$ ( $2 \mathrm{wt} \%$ ) phosphate ionophore I, $5.7 \mathrm{mmol} / \mathrm{kg}(0.3 \mathrm{wt} \%)$ TDMAC, 32.60 wt \% PVC and 66.25 wt \% $o$-NPOE. The components totaling $140 \mathrm{mg}$ were dissolved in $1.4 \mathrm{~mL}$ THF and poured into a glass ring (i.d. $21 \mathrm{~mm}$ ), giving ca. 200 $\mu \mathrm{m}$ thick membranes.

Electrodes. A 6-mm diameter disc was cut from the membrane and glued to plasticized PVC tubing with a THF/PVC slurry and the electrode assembled as described [36]. A mixture of $\mathrm{NaH}_{2} \mathrm{PO}_{4}$ and $\mathrm{NaCl}$ of the concentration of $10^{-2} \mathrm{M}$ was used as an inner solution. Electrodes were conditioned over night in a $10^{-2} \mathrm{M} \mathrm{NaH}_{2} \mathrm{PO}_{4}$ solution.

EMF measurements. Potentials were monitored through a PCI MIO16XE data acquisition board (National Instruments, Austin, TX) utilizing a 4 Channel High Z Interface (WPI, Sarasota, FL) at room temperature $\left(22{ }^{\circ} \mathrm{C}\right)$, in the galvanic cell: $\mathrm{Ag} / \mathrm{AgCl} / 3 \mathrm{M} \mathrm{KCl} / 1 \mathrm{M}$ LiOAc/sample solution/ISE membrane/10-2 $\mathrm{M}\left(\mathrm{NaH}_{2} \mathrm{PO}_{4}+\mathrm{NaCl}\right) / \mathrm{AgCl} / \mathrm{Ag}$ with a double-junction reference electrode (type 6.0729.100, Methrom AG, CH-9101 Herisau, Switzerland). The experiments were performed in a $100-\mathrm{mL}$ polyethylene beaker. All 
EMF values were corrected for liquid-junction potentials according to the Henderson equation. Activity coefficients were calculated by the Debye-Hückel approximation.

Thin optode film preparation. Unless otherwise indicated, a mixture of $27 \mathrm{mmol} / \mathrm{kg}$ phosphate ionophore I or II, $6 \mathrm{mmol} / \mathrm{kg}$ TDMAC, $2.3 \mathrm{mmol} / \mathrm{kg}$ ETH 5350 or ETH 5294 in plasticized PVC (1:2 by mass), with a total mass of $90 \mathrm{mg}$ was dissolved in $2 \mathrm{ml}$ THF. Alternatively, for the two component optode-sensors a cocktail containing $18 \mathrm{mmol} / \mathrm{kg}$ phosphate ionophore I and $7.3 \mathrm{mmol} / \mathrm{kg}$ ETH 5350 was prepared. To prepare the film, $50-\mu \mathrm{L}$ of this cocktail was pipetted onto a Fisherbrand $22 \mathrm{~mm}$ (No. 1) square cover glass and immediately placed in darkness for 30 min until the THF was fully evaporated.

Particle preparation. Fluorescent microspheres were prepared using a sonic particlecasting apparatus $[28,30]$. The sensing cocktail containing $39.7 \mathrm{mmol} / \mathrm{kg}$ phosphate ionophore I, $7.2 \mathrm{mmol} / \mathrm{kg}$ TDMAC, $4.1 \mathrm{mmol} / \mathrm{kg}$ ETH 5350, and PVC/o-NPDDE (1:2) was dissolved in $2.5-\mathrm{mL}$ cyclohexanone, diluted with $50-\mathrm{mL}$ of ethyl acetate and filtered with a $0.45-\mu \mathrm{m}$ syringe filter to remove any solid impurities. The following setup was applied: a ceramic tip with a $48 \mu \mathrm{m}$ diameter orifice, a $0.75 \mathrm{~mL} / \mathrm{min}$ water stream flow rate, $20.2 \mathrm{kHz}$ frequency and $0.58 \mathrm{~mL} / \mathrm{min}$ polymer flow rate. Microspheres were collected in 10-mL glass vials and stored after casting in the dark for one day in order to remove residual solvent from the particles and to allow the microspheres to sediment.

Sample solutions. Calibration curves and selectivity were recorded in $15 \mathrm{mM}$ buffer solutions (MES-NaOH of pH 4.7 and $\mathrm{pH}$ 7.0) containing the appropriate electrolytes. All calibrating solutions were prepared in polyethylene beakers.

Instruments. A PARISS Imaging Spectrometer (Light Form, Belle Mead, NJ) in combination with a Nikon Eclipse E400 microscope was used to characterize the optodefilms and microspheres. A fluorescence spectrophotometer F-7000 (Hitachi, San Jose, CA) was used for the inner filter effect experiments.

Procedures. Thin optode films and microspheres were equilibrated in 30-mL sample solutions for about 30 minutes before measurement. Calibration curves were recorded in $10^{-6}-10^{-1} \mathrm{M}$ buffered $\mathrm{NaH}_{2} \mathrm{PO}_{4}$ solutions at $\mathrm{pH} 4.7$ and 7.0. Selectivity coefficients were evaluated using the separate solutions method (SSM) as the horizontal distance between logarithmic activities of primary and interfering ions at $\alpha=0.5$ and at $\mathrm{pH} 4.7$ and 7.0, as 
established [23, 37]. The exposure time for the fluorescence data acquisition was $300 \mathrm{~ms}$. Full protonation and deprotonation spectra of the chromoionophore ETH 5294 and ETH 5350 were recorded at $10 \mathrm{mM} \mathrm{HCl}$ and $10 \mathrm{mM} \mathrm{NaOH}$, respectively. Ratiometric measurements were performed by comparing the fluorescence emission peaks at 678/648 nm (ETH 5294), and 667/610 nm (ETH 5350).

Measurements in blood. The blood samples (HemoStat Laboratories, Dixon CA) were stored at $4^{\circ} \mathrm{C}$. An aliquot ( 1 or $5 \mathrm{~mL}$ ) of blood was placed into a polypropylene beaker with or without standard addition of a measured amount of sodium dihydrogen phosphate, and diluted to 100-mL with MES buffer. 


\section{Results and discussion}

Our aim is design robust particle based optodes for the selective determination of dihydrogen phosphate ions. Although much effort has been devoted to phosphate sensor fabrication and various ligands have been proposed for this purpose, the resulting sensors were often found to suffer from either transient, non-Nernstian response characteristic or a very limited life-time. Here, two promising salophene-based neutral carriers formerly characterized in ISEs [38], phosphate ionophore I and II, were selected for incorporation in optical sensing films.

The proposed optode-based dihydrogen phosphate sensor is based on an established coextraction equilibrium step [23], where an appropriate fluoroionophore is required in the sensing film in addition to the phosphate-selective receptor. Upon contact with the sample, $\mathrm{H}_{2} \mathrm{PO}_{4}{ }^{-}$ions and hydrogen ions are mutually extracted into the polymeric phase for electroneutrality reasons, which leads to the protonation of the fluoroionophore according to the following scheme:

$\mathrm{X}_{(\mathrm{aq})}^{-}+\mathrm{H}_{(\mathrm{aq})}^{+}+\mathrm{nL}_{(\mathrm{org})}+\mathrm{Ind}_{(\mathrm{org})}==\mathrm{L}_{\mathrm{n}} \mathrm{X}_{(\mathrm{org})}^{-}+\mathrm{IndH}_{(\mathrm{org})}^{+}$

where Ind denotes the fluoroionophore, $\mathrm{L}$ the ionophore and $\mathrm{X}$ the dihydrogen phosphate ion. The resulting optode response function, i.e. the relationship between the sample activities of the ion $a_{\mathrm{X}^{-}}$and $a_{\mathrm{H}^{+}}$and the fluorescence signal may be approximated by the following equation [27]:

$a_{X^{-}} a_{H^{+}}=\left(K_{c o e x}\right)^{-1}\left(\frac{1-\alpha}{\alpha}\right) \frac{(1-\alpha) \cdot \operatorname{Ind}_{T}}{\left(L_{T}-n(1-\alpha) \cdot \operatorname{Ind}_{T}\right)^{n}}$

where $(1-\alpha)$ is the degree of protonation of the chromoionophore, $K_{\text {coex }}$ is the coextraction constant that describes equation $1, \mathrm{n}$ is ion-ionophore complex stoichiometry, and subscripts $\mathrm{T}$ denote the total concentration of the indicated species.

The fluorescence signal is expressed as the mole fraction of unprotonated fluoroionophore, $\alpha$, which may be approximately related to the fluorescence signal as:

$$
\alpha=\frac{[\mathrm{Ind}]}{\operatorname{Ind}_{\mathrm{T}}}=\left(1+\frac{\mathrm{R}_{\max }-\mathrm{R}}{\mathrm{R}-\mathrm{R}_{\text {min }}}\right)^{-1}
$$


where $\mathrm{R}, \mathrm{R}_{\min }$, and $\mathrm{R}_{\max }$ are the fluorescence intensity ratios (at two wavelengths) for a given equilibrium and at minimum and maximum protonation of the fluoroionophore, respectively.

Here, several types of optode films were studied. The influence of the chemical composition on their performances and selectivity is summarized in Table 1.

Thus far, bis(2-ethylhexyl)sebacate (DOS, $\varepsilon=4.6$ [39]) has been the plasticizer of choice for ion-selective optode films and microsphere sensors [25, 27-30], owing to its relatively high lipophilicity. However, to facilitate the extraction of the hydrophilic dihydrogen phosphate ion into an organic optode phase, a plasticizer of higher polarity was required. Figure 1 displays the response characteristic of thin optodes films of identical composition, but plasticized with either DOS, $o$-nitrophenyl dodecyl ether ( $o$-NPDDE) or $o$-nitrophenyl octyl ether (o-NPOE). The latter was found to be most suited in terms of optical response characteristics with the desired measuring range. Optodes cast with the more lipophilic o-NPDDE exhibited slightly worse working parameters compared to those containing $o$-NPOE. In contrast, a drastic shift of about 3 orders of magnitude toward higher concentration was observed in case of optode films cast with DOS. Note that these differences are normally much less pronounced with cation-selective optodes that operate on the basis of competitive ion-exchange processes [23].

These experiments were carried out at a $\mathrm{pH}$ of 4.7 , under which conditions dihydrogen phosphate is the predominant form of phosphate. Chromionophore I (ETH 5294, pKa = 12.0) [40, 41] was used for initial characterization. In order to decrease the optode equilibration time, anion-exchanger sites (TDMAC) were incorporated into the optode composition (see also [23]). Figure 2 (top) displays the response toward dihydrogen phosphate and the corresponding selectivity sequence for thin optode films doped with ETH 5294/phosphate ionophore I/TDMAC. Although the recorded response characteristic and selectivity was attractive, the measuring range was not desirable in view of the application to physiological samples.

It is well known that the measuring range of bulk optode-based sensors is normally quite narrow, especially if monovalent ions are measured. This range may be shifted by changing the optode composition, varying the sample $\mathrm{pH}$ and/or changing the 
fluoroionophore [23, 24]. Indeed, the use of the more basic fluoroionophore ETH 5350 (pKa of $13.4[40,41]$ ) shifted the optode films measuring range to a lower concentration, with an observed shift equal to $\Delta \mathrm{pKa}$ as predicted by bulk optode theory [23, 24].

Figure 2 (bottom) illustrates the response characteristic and selectivity of optode films doped with ETH 5350/phosphate ionophore I/TDMAC. The data points were fitted to the theoretical curve with $\mathrm{n}=2$, confirming the complex stoichiometry reported earlier [34]. Note that the experimental data points are in good agreement with theory (solid lines obtained using equation 2). The small error bars $(\mathrm{n}=5)$ indicate good sensor reproducibility. The selectivity data, calculated as the horizontal difference between corresponding curves for the degree of protonation $(1-\alpha)$ equal 0.5 , are summarized in Table 1 . The selectivity coefficients are comparable to that of the corresponding ISEs [38]. The most interfering ion in physiological samples, chloride, was also well discriminated against.

Optode films doped with ETH 5350/phosphate ionophore II/TDMAC also exhibited an excellent response to dihydrogen phosphate. The calculated selectivity coefficients were slightly better (see Table 1) than those observed for sensors containing phosphate ionophore I. Unfortunately, these sensors were found to suffer from a limited lifetime (see also below).

Further attempts were made to tune the measuring range by applying a highly basic fluoroionophore. Unfortunately, the lipophilic fluorescein derivatives incorporated in plasticized PVC [42] were found to exhibit very poor fluorescence emission intensity. A number of preliminary experiments based on the inner filter effect utilizing films doped with ETH 7075 (chromoionophore VI) and $\mathrm{DiOC}_{14}(3)$ were performed. Unfortunately, this approach resulted in nonfunctional optode sensors, i.e. no phosphate response was observed (data not shown).

An elimination of the anion-exchanger sites should lead to an increase in the ratio of uncomplexed to complexed ionophore in the sensing films, thereby further shifting the measuring range to lower concentrations. Figure 3 shows the recorded response characteristics toward dihydrogen phosphate for optode films doped with ETH 5350/phosphate ionophore I. Indeed, elimination of the ionic sites from the composition 
allowed us to shift the optode response range by about one order of magnitude in the desired direction. Note that the experimental data points are in very good agreement with the theoretically predicted curves. The expected selectivity pattern was also preserved. However, the time required for full equilibration was much longer (ca. $40 \mathrm{~min}$ ) compared to optodes containing TDMAC. This suggests an attractive catalytic function of the anion-exchanger, similar to what has been observed earlier with optical sensors for ethanol [43].

From a practical standpoint, it would be desirable to perform measurements at physiological $\mathrm{pH}$, rather than the value of 4.7 typically chosen for dihydrogen phosphate sensors. Figure 4 (top) displays the response characteristic of the two component optodefilms and their ISE counterparts (bottom) at $\mathrm{pH}$ 7.0. A shift of the optode response toward higher concentration range was observed, as expected. Indeed, the data points agree with the theoretically predicted curve with the same coextraction constant value $\left(\log \mathrm{K}_{\mathrm{coex}}=10.9\right)$ after respecting for the speciation of phosphate. At neutral $\mathrm{pH}$, a significant interference of hydroxide ion is observed with ISEs [44], which may explain the sub-Nernstian slope of the potentiometric sensor of about $-37 \mathrm{mV} / \mathrm{dec}$ as shown in Figure 4, bottom. In contrast, optical sensors may exhibit analytically useful phosphate responses at physiological $\mathrm{pH}$ because the hydroxide ion is no longer regarded an interferent, but is part of the measurement equilibrium, see equation 1. At this $\mathrm{pH}$, dihydrogen phosphate ions comprise a much smaller fraction of phosphate species in solution, and only a mM detection limit was achieved.

Uranyl salophene derivatives have been known to be highly selective dihydrogen phosphate carriers. However, ISE membranes doped with these compounds are known to suffer from a limited lifetime, mainly due to ionophore decomposition in contact with phosphate [44, 45]. An innovative attempt to extend the electrode lifetime has been reported by Wojciechowski et al. using an anion buffer in the internal electrolyte, leading to a siphoning off of phosphate from the membrane and hence increasing the chemical lifetime of the ionophore [38] If the optode films prepared here were constantly exposed to dihydrogen phosphate solutions, morphological changes of the films were observed, independent of the ionophore used. The films became cloudy and were no longer homogeneous (data not shown). A corresponding deterioration of the experimental data 
points from the theoretical curve was observed. This phenomenon was much more rapid in the case of optode-films fabricated with phosphate ionophore II and their life-time was no longer than 1 day. The loss of optode functionality was probably due to a combination of ionophore leakage (lower lipophilicity), plasticizer leakage, and ionophore decomposition upon contact with dihydrogen phosphate ions as reported earlier $[38,45$, 46].

The long term stability of the sensors was found to depend on the fluoroionophore structure. Chromionophore I is known to exhibit unstable behavior under some conditions [47]. Typically, ETH 5294 exhibits two emission peaks at $\lambda=648$ and $\lambda=680 \mathrm{~nm}$, which correspond to the deprotonation and protonation of the fluorophore, respectively. Within a few hours a shoulder at $\lambda=610 \mathrm{~nm}$ became predominant, suggesting the decomposition of ETH 5294. The spectral changes were followed by the visible leaching of membrane components, as the contacting aqueous solution became green. Optodes cast with ETH 5350 did not exhibit such spectral changes. The loss of optode functionality was faster ( 2 days) in the case of sensors containing ion-exchanger sites, which is in agreement with phosphate induced destabilization of the ionophore because of the increased phosphate concentration in the sensing films under such conditions. The lifetime of two component optode sensors was enhanced to about 5 days (data not shown). The life-time of optode films cannot be directly compared to that of ISEs [38] because optode films were here continuously stored in dihydrogen phosphate solutions and optode films are significantly thinner compared to ISE membranes. This may not be a drawback in practical applications because there is no need to precondition optodes with the analyte as is often required with ISEs.

These studies formed the basis for the fabrication of microsphere optodes based on a ultrasonically vibrating dual stream casting apparatus reported previously [28-30]. Due to its high polarity and partial water solubility, $o$-NPOE could not be used for particle preparations (see also [27]). To prevent plasticizer from leaching during the casting process, microspheres were cast using the more lipophilic o-NPDDE. Although two component optode films exhibited better working parameters (see above), optode 
microspheres of analogous composition were not found to be functional and no response toward dihydrogen phosphate was observed.

Figure 5 displays the reproducibility, response characteristics and selectivity of optodemicrospheres containing ion-exchanger sites. The response characteristics of the microspheres doped with phosphate ionophore I/ETH 5350/TDMAC was in good agreement with the data obtained for analogous optode films, see above. The standard deviations (shown as error bars) were calculated from at least 10 particles. The lifetime of the microspheres was quite short. After a few hours of exposure to dihydrogen phosphate ions, drastic changes and large variations in microsphere responses were recorded (data not shown). This strongly suggests that the contact of such optode microspheres with phosphate containing solutions should be avoided before measurement.

Optode sensors were explored in preliminary experiments for the measurement of phosphate in sheep plasma samples, which has inorganic phosphate levels of around 1 $\mathrm{mM}$. The phosphate level was examined for a series of diluted blood samples (1:100 and 1:20) buffered to $\mathrm{pH} 4.7$ and samples prepared by standard addition using optode films and optode-microsphere sensors (see Table 2). For each dilution 3 samples were examined. Note the very good reproducibility between data obtained for the samples. The average phosphate concentration for the original sample determined with thin optode films was calculated as $(9.4 \pm 0.1) \times 10^{-4} \mathrm{M}(\log \mathrm{c}=-3.026 \pm 0.005)$.

In comparison, measurements of 100 and 20-fold diluted samples with optode microspheres yielded a logarithmic phosphate concentration of $\log \mathrm{c}=-3.04(\mathrm{n}=10$ microspheres). The average phosphate concentration was established as $\log \mathrm{c}=3.038 \pm$ $0.002(9.2 \pm 0.1) \times 10^{-4} \mathrm{M}$ calculated for the original sample. The calculated phosphate level was in accordance with the data achieved for the thin optode films, suggesting that the underlying chemistry may be adequate for the direct selective assay of inorganic phosphate in physiological samples. 


\section{Conclusions}

This paper introduces the first chemically selective fluorescent dihydrogen phosphatesensing optode films and optode microspheres reported in the literature. The chemical selectivity and measuring range for optimized membranes are adequate for measurement in weakly acidic samples $(\mathrm{pH}$ 4.7) where dihydrogen phosphate is the dominant form of inorganic phosphate. Measurements at $\mathrm{pH} 7.0$ are entirely possible and correspond to theoretical expectations if the speciation of phosphate is taken into account, which is in contrast to corresponding ion-selective electrodes where hydroxide interference becomes problematic. However, the lower activity of dihydrogen phosphate in relation to other interferences such as chloride places a limit on the detectable lower concentration, and millimolar detection limits are observed. The realization of a microsphere sensing format for these optodes was successful, but some compromise in terms of sensing film composition needed to be made to maintain adequate sensor function. Upon continuous contact with phosphate containing samples, the lifetime of the optical phosphate sensors are on the order of days for film based systems and hours for the microspheres. While this is likely adequate for routine measurements, such sensors cannot be stored in phosphate containing environments. Preliminary experiments on blood plasma samples were promising and suggest that uranyl salophenes may be attractive for the measurement of phosphate in physiological samples. 


\section{Acknowledgments}

The authors wish to thank Beckman-Coulter, Inc. for financial support of this research and Kyle Brizan and Junhua Xin (group of Curtis Shannon, Auburn University) for technical assistance. 
Table 1. Logarithmic selectivity coefficients $\log \mathrm{K}_{\mathrm{I}, \mathrm{J}}^{\mathrm{Osel}}$ for the thin-optode films observed at $\mathrm{pH}$ $=4.7$ and $(1-\alpha)=0.5$.

\section{PVC/o-NPOE}

\section{ETH 5294}

ETH 5350

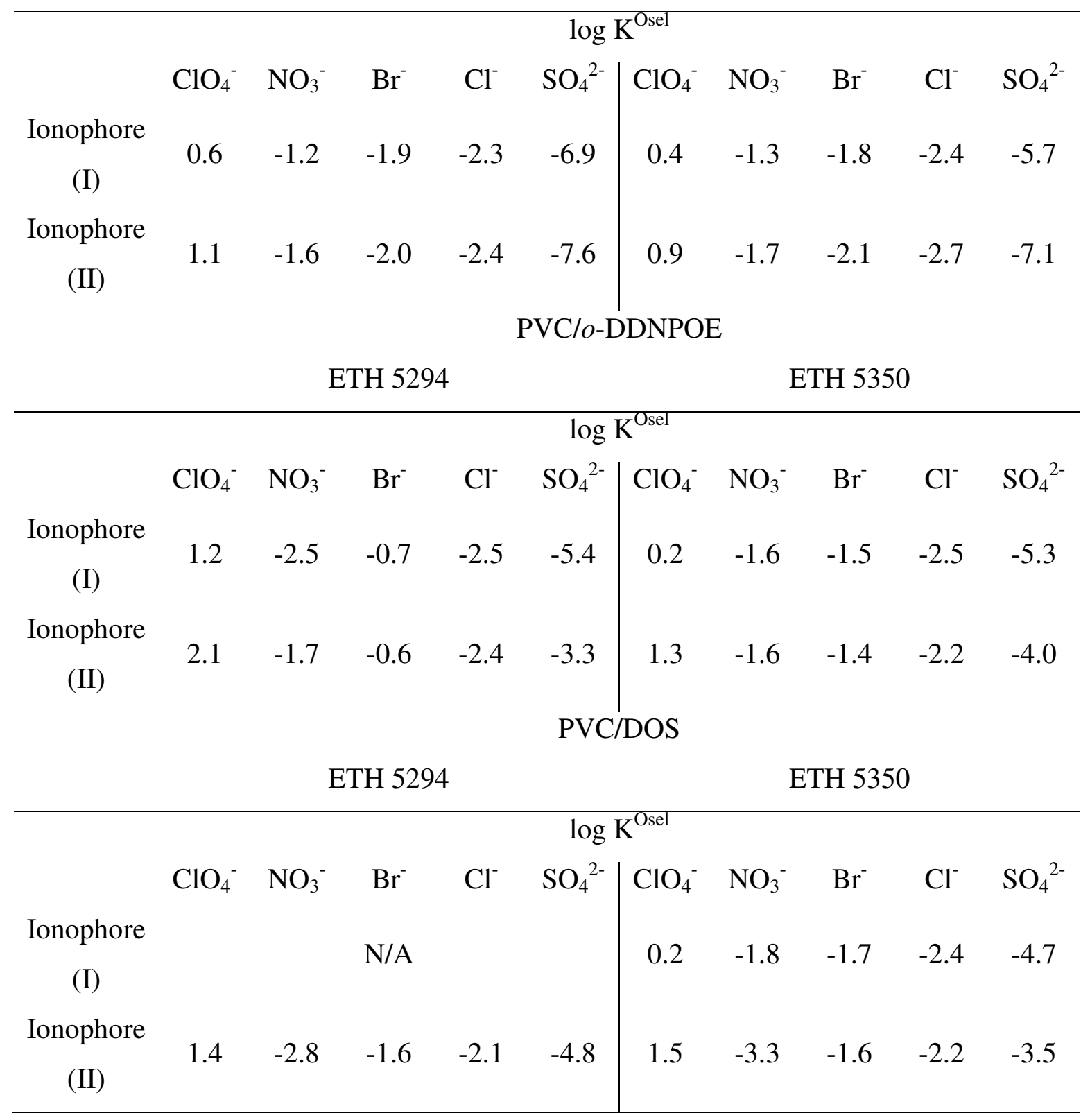


Table 2. Observed original dihydrogen phosphate concentration in blood samples for thin optode films and optode-microspheres sensors.

\begin{tabular}{|c|c|c|c|c|c|}
\hline \multicolumn{7}{|c|}{ Optode films } \\
\hline $\begin{array}{c}\text { Sample } \\
\text { dilution }\end{array}$ & $1: 100$ & $1: 100^{\mathrm{a}}$ & $1: 100^{\mathrm{b}}$ & $1: 20$ & $1: 20^{\mathrm{c}}$ \\
\hline $\begin{array}{c}\text { Found log } c \\
\mathrm{H}_{2} \mathrm{PO}_{4}{ }^{-}\end{array}$ & -3.030 & -3.019 & -3.027 & -3.028 & -3.026 \\
& \pm 0.007 & \pm 0.004 & \pm 0.003 & \pm 0.001 & \pm 0.005 \\
\hline $\begin{array}{c}\text { Sample } \\
\text { dilution }\end{array}$ & $1: 100$ & $1: 100^{\mathrm{d}}$ & $1: 20$ & $1: 20^{\mathrm{e}}$ \\
\hline $\begin{array}{c}\text { Found log } c \\
\mathrm{H}_{2} \mathrm{PO}_{4}{ }^{-}\end{array}$ & -3.04 & -3.039 & -3.034 & -3.035 \\
& \pm 0.003 & \pm 0.002 & \pm 0.002 & \pm 0.003 \\
\hline
\end{tabular}

Subscripts denote the following standard additions of dihydrogen phosphate to the sample (100 $\mathrm{mL}$ final volume): ${ }^{\mathrm{a}} 1 \mathrm{~mL} 10^{-3} \mathrm{M} ;{ }^{\mathrm{b}} 1 \mathrm{~mL} 10^{-2} \mathrm{M} ;{ }^{\mathrm{c}} 2 \mathrm{~mL} 0.05 \mathrm{M} ;{ }^{\mathrm{d}} 1.5 \mathrm{~mL} 10^{-2} \mathrm{M} ;{ }^{\mathrm{e}} 1 \mathrm{~mL} 10^{-2}$ M. 


\section{Literature Cited}

[1] R. L. Benson, I. D. McKelvie, B. T. Hart, Y. B. Truong, I. C. Hamilton, Anal. Chim. Acta, 326 (1996) 29.

[2] Y. Udnan, I. D. McKelvie, M. R. Grace, J. Jakmunee, K. Grudpan, Talanta, 66 (2005) 461.

[3] M. Grace, Y. Udnan, I. McKelvie, J. Jakmunee, K. Grudpan, Environ. Chem., 3 (2006) 19.

[4] M. S. Han, D. H. Kim, Angew. Chem. Int. Ed., 41 (2002) 3809.

[5] D. A. Jose, D. K. Kumar, B. Ganguly, A. Das, Tetrahedron Lett., 46 (2005) 5343.

[6] S. Sasaki, D. Citterio, S. Ozawa, K. Suzuki, J. Chem. Soc., Perkin Trans., 2 (2001) 2309.

[7] S. R. Crouch, H. V. Malmstadt, Anal. Chem., 39 (1967) 1084.

[8] T. Osakai, S. Himeno, A. Saito, H. Katano, Electroanalysis, 5 (1993) 275.

[9] E. M. D'Urso, P. R. Coulet, Anal. Chim. Acta, 281 (1993) 535.

[10] E. M. D'Urso, P. R. Coulet, Anal. Chim. Acta, 239 (1990) 1.

[11] Y. Su, M. Mascini, Anal. Lett., 28 (1995) 1359.

[12] J. C. Quintana, L. Idrissi, G. Palleschi, P. Albertano, A. Amine, M. El Rhazi, D. Moscone, Talanta, 63 (2004) 567.

[13] D. Liu, C. W. Chen, R. H. Yang, G. L. Shen, R. Q. Yu, Anal. Chim. Acta, 338 (1997) 209.

[14] D. Xiao, H. Y. Yuan, J. Li, R. Q. Yu, Anal. Chem., 67 (1995) 288.

[15] J. Liu, Y. Masuda, E. Sekido, S. Wakida, K. Hiiro, Anal. Chim. Acta, 224 (1989) 145.

[16] M. Fibbioli, M. Berger, F. P. Schmidtchen, E. Pretsch, Anal. Chem., 72 (2000) 156.

[17] C. M. Carey, W. B. Rlggan, Anal. Chem., 66 (1994) 3587.

[18] S. A. Glazier, M. A. Arnold, Anal. Chem., 60 (1988) 2542.

[19] N. A. Chaniotakis, K. Jurkschat, A. Ruehlemann, Anal. Chim. Acta, 282 (1993) 345. 
[20] K. N. Mikhel'son, A. L. Smirnova, N. A. Malysh, Elektrokhimiya, 30 (1994)

[21] T. Le Goff, J. Braven, L. Ebdon, D. Scholefield, Anal. Chim. Acta, 510 (2004) 175.

[22] M. R. Ganjali, F. Mizani, M. S. Niasari, Anal. Chim. Acta, 481 (2003) 85.

[23] E. Bakker, P. Buehlmann, E. Pretsch, Chem. Rev., 97 (1997) 3083.

[24] M. Lerchi, F. Orsini, Z. Cimerman, E. Pretsch, D. A. Chowdhury, S. Kamata, Anal. Chem., 68 (1996) 3210.

[25] K. Wygladacz, E. Bakker, Anal. Chim. Acta, 532 (2005) 61.

[26] C. Xu, K. Wygladacz, Y. Qin, R. Retter, M. Bell, E. Bakker, Anal. Chim. Acta, 537 (2005) 135.

[27] A. Ceresa, Y. Qin, S. Peper, E. Bakker, Anal. Chem., 75 (2003) 133.

[28] I. Tsagkatakis, S. Peper, R. Retter, M. Bell, E. Bakker, Anal. Chem., 73 (2001) 6083.

[29] K. Wygladacz, E. Bakker, Analyst, 132 (2007) 268.

[30] K. Wygladacz, A. Radu, C. Xu, Y. Qin, E. Bakker, Anal. Chem., 77 (2005) 4706.

[31] M. M. G. Antonisse, B. H. M. Snellink-Rue, J. F. J. Engbersen, D. N. Reinhoudt, J. Org. Chem., 63 (1998) 9776.

[32] M. M. G. Antonisse, B. H. M. Snellink-Rue, I. Yigit, J. F. J. Engbersen, D. N. Reinhoudt, J. Org. Chem., 62 (1997) 9034.

[33] H. C. Visser, D. M. Rudkevich, W. Verboom, F. De Jong, D. N. Reinhoudt, J. Am. Chem. Soc., 116 (1994) 11554.

[34] M. M. G. Antonisse, B. H. M. Snellink-Rueel, J. F. J. Engbersen, D. N. Reinhoudt, J. Org. Chem., 63 (1998) 9776.

[35] M. M. G. Antonisse, B. H. M. Snellink-Ruel, J. F. J. Engbersen, D. N. Reinhoudt, Sens. Actuators, B, 47 (1998) 9.

[36] A. Radu, M. Telting-Diaz, E. Bakker, Anal. Chem., 75 (2003) 6922.

[37] E. Bakker, W. Simon, Anal. Chem., 64 (1992) 1805.

[38] K. Wojciechowski, W. Wroblewski, Z. Brzozka, Anal. Chem., 75 (2003) 3270. 
[39] R. Eugster, T. Rosatzin, B. Rusterholz, B. Aebersold, U. Pedrazza, D. Riiegg, A. Schmid, U. E. Spichiger, W. Simon, Anal. Chim. Acta, 289 (1994) 1.

[40] E. Bakker, M. Lerchi, T. Rosatzin, B. Rusterholz, W. Simon, Anal. Chim. Acta, 287 (1993) 211.

[41] E. Lindner, T. Rosatzin, J. Jeney, V. V. Cosofret, W. Simon, R. P. Buck, J. Electroanal. Chem., 352 (1993) 309.

[42] S. S. S. Tan, P. C. Hauser, K. Wang, K. Fluri, K. Seiler, B. Rusterholz, G. Suter, M. Krüttli, U. E. Spichiger, W. Simon, Anal. Chim. Acta, 255 (1991) 35.

[43] K. Seiler, K. M. Wang, M. Kuratli, W. Simon, Anal. Chim. Acta, 244 (1991) 151.

[44] M. M. G. Antonisse, Anion Recognition and Sensing, Ph.D. Thesis, University of Twente, 1998.

[45] K. Wojciechowski, W. Wroblewski, Z. Brzozka, Mater. Sci. Eng., C, C18 (2001) 93.

[46] K. Wojciechowski, W. Wroblewski, Z. Brzozka, Polish J. Chem., 76 (2002) 671.

[47] J. Langmaier, E. Lindner, Anal. Chim. Acta, 543 (2005) 156. 


\section{Figure Captions}

Figure 1 Dihydrogen phosphate response characteristics at $\mathrm{pH} 4.7$ for thin optode films containing different plasticizers: $4.7 \mathrm{mmol} / \mathrm{kg}$ phosphate ionophore $\mathrm{I}, 2.3 \mathrm{mmol} / \mathrm{kg}$ ETH 5350, PVC/DOS (1:2); $6.6 \mathrm{mmol} / \mathrm{kg}$ phosphate ionophore I, $2.7 \mathrm{mmol} / \mathrm{kg} \mathrm{ETH}$ 5350, PVC/o-NPDDE (1:2); $6.6 \mathrm{mmol} / \mathrm{kg}$ phosphate ionophore I, $2.7 \mathrm{mmol} / \mathrm{kg}$ ETH 5350, PVC/o-NPOE (1:2).

Figure 2 Response function and ion selectivity of dihydrogen phosphate optode films characterized at $\mathrm{pH}$ 4.7. Optode-film compositions are (A) $24.9 \mathrm{mmol} / \mathrm{kg}$ phosphate ionophore I, $6.1 \mathrm{mmol} / \mathrm{kg}$ TDMAC, $2.6 \mathrm{mmol} / \mathrm{kg}$ ETH 5294 and (B) $24.1 \mathrm{mmol} / \mathrm{kg}$ phosphate ionophore I, $6.1 \mathrm{mmol} / \mathrm{kg}$ TDMAC, $2.6 \mathrm{mmol} / \mathrm{kg}$ ETH 5350. Theory according to eq 2 with $\log \mathrm{K}_{\text {coex }}=8.3$ and $\log \mathrm{K}_{\mathrm{coex}}=9.32$ for the sensors doped with ETH 5394 and ETH 5350, respectively. (C) Structures of the two ionophores used in this study.

Figure 3 Response function and selectivity of two component thin optode films containing phosphate ionophore I and ETH 5350, characterized at $\mathrm{pH}$ 4.7. Solid line: equation 2 with $\log \mathrm{K}_{\mathrm{coex}}=10.9$.

Figure 4 Response function and selectivity of the two component thin optode films (see Figure 3, top) and their ISE counterparts (bottom) characterized at $\mathrm{pH}$ 7.0.

Figure 5 Size distribution of fluorescent dihydrogen phosphate-selective microspheres observed with a 10x microscope objective (top), response characteristics and selectivity of the three component optode microspheres recorded at $\mathrm{pH}$ 4.7. The particle contained phosphate ionophore I, TDMAC and ETH 5350. Solid line: equation 2 with $\log \mathrm{K}_{\text {coex }}=9.3$. 